\title{
Muscular rim sign at endoscopic ultrasound in a patient with a suspected cyst of the pancreatic head
}

\author{
G. Marasco', R. Sadik ${ }^{2}$ \\ (1) Department of Medical and Surgical Sciences, University of Bologna, Bologna, Italy ; (2) Department of Internal Medicine, Institute of Medicine, Sahlgrenska Academy, \\ University of Gothenburg, Göteborg, Sweden.
}

Keywords : Duodenal mucosa, endoscopic ultrasonography, pancreatic pseudocyst, duplication cyst.

\section{Case}

A 67 years old male patient was referred in September 2019 to the Gastroenterology and Endoscopy Unit of the Sahlgrenska University Hospital, in Göteborg (Sweden), to undergo an endoscopic ultrasound (EUS) examination. The patient was asymptomatic, without other relevant gastroenterological comorbidities and referred for the suspicion of a pancreatic cyst and/or intraductal papillary mucinous neoplasia (IPMN) of the pancreatic head; the suspicion was raised by a recent magnetic resonance imaging (MRI) examination performed in our center for other reasons.

Multiple EUS scans excluded any pancreatic cysts. The endoscopic view of the duodenum confirmed the presence of both the minor and the major duodenal papilla. However, just below the major duodenal papilla, a mucosal bulging extended for 2.5 centimeters, with normal mucosa and with a papilla-like orifice in the proximal part was found (Figure 1a) and evaluated with EUS (Figure 1b).

What is the diagnosis on the basis of the EUS image?

\section{Answer}

The EUS evaluation of the mucosal bulging showed a typical gastrointestinal multi-layered, well-delimited anechoic structure in the second portion of the duodenum of $19 \times 12 \mathrm{~mm}$, arising from the submucosa and directly communicating with duodenal lumen. The arrow indicates the 'muscular rim sign' consisting in the presence of echogenic mucosa inside the cyst and hypoechoic muscle layer outside the cyst. Thus, duodenal duplication cyst diagnosis was made.

Duplication cysts are rare congenital lesions, presenting with a cystic or tubular shape, potentially occurring anywhere in the alimentary tract. The cysts are composed of a well-developed muscular wall with epithelial mucosal lining and an intimate attachment to the native gastrointestinal tract. Duodenal duplication cysts are rare and reported only in $5-7 \%$ of cases $(1,2)$. Clinician should be aware of these cysts since they can contain ectopic gastric mucosa in $35 \%$ of cases and cause pain, bleeding, peptic ulcer as well as malignancy (2). Differential diagnosis with choledochoceles, intraluminal duodenal diverticulum and pancreatic cyst/ pseudocyst is difficult with computed tomography and MRI (3). Recently, EUS has been reported as accurate

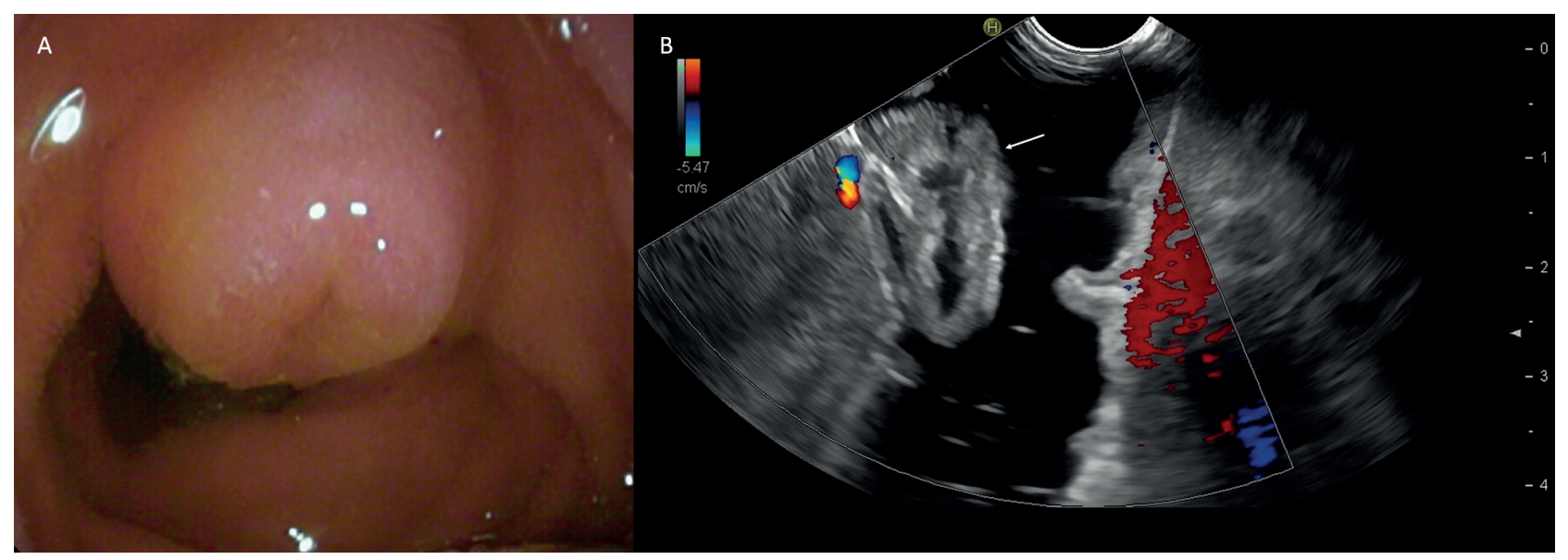

Figure 1. - A) Endoscopic view of duodenal mucosal bulging and a papilla-like orifice in the proximal part ; B) Endoscopic ultrasound evaluation of the duodenal mucosal bulging; the white arrow points on the 'muscular rim sign'.
Correspondence to : Giovanni Marasco, M.D., Ph.D. Department of Medical and Surgical Sciences, University of Bologna, Via Massarenti 9, 40126 Bologna, Italy. Phone : +390512143357 .

E-mail : giovannimarasco89@gmail.com

Submission date : 26/03/2020

Acceptance date : 30/05/2020 
for diagnosis of duodenal duplication cysts(3). As regard treatment, endoscopic treatment may be a useful alternative to surgery in absence of malignancy (1).

\section{Conflict of interest and financial disclosures}

None to declare.

\section{Acknowledgments}

We want to thank United European Gastroenterology Association for allowing this collaboration to start through the 'Visiting Fellowship Program for Clinicians'.

\section{References}

1. GJEORGJIEVSKI M, MANICKAM P, GHAITH G, CAPPELL MS. Safety and Efficacy of Endoscopic Therapy for Nonmalignant Duodenal Duplication Cysts. Medicine (Baltimore), 2016, 95 : e3799.

2. REDONDO-CEREZO E, PLEGUEZUELO-DÍAZ J, HIERRO ML DE, MACIAS-SÁNCHEZ JF, VIÑOLO UBIÑA C, MARTÍN-RODRÍGUEZ M DEL M, et al. Duodenal duplication cyst and pancreas divisum causing acute pancreatitis in an adult male. World J. Gastrointest. Endosc., 2010, 2 : 318-20. 3. FAIGEL DO, BURKE A, GINSBERG GG, STOTLAND BR, KADISH SL, KOCHMAN ML. The role of endoscopic ultrasound in the evaluation and management of foregut duplications. Gastrointest. Endosc., 1997, 45 : 99-103. 